Recebido em 11/2019. Aceito para publicação em 12/2019.

\title{
AVALIAÇÃO DAS PROPRIEDADES MECÂNICAS DE RESISTÊNCIA À COMPRESSÃO E À FLEXÃO DO CONCRETO COM SUBSTITUIÇÃO PARCIAL DE PLACA DE CIRCUITO IMPRESSO NO AGREGADO GRAÚDO EM ATÉ 30\%
}

\section{EVALUATION OF THE MECHANICAL PROPERTIES OF RESISTANCE TO COMPRESSION AND FLEXION OF CONCRETE WITH PARTIAL REPLACEMENT OF PRINTED CIRCUIT BOARD IN THE AGGREGATE IN UP TO $30 \%$}

\author{
Leonardo Alves da Conceição ${ }^{1}$ \\ Ricardo de Freitas Cabral ${ }^{2}$ \\ Roberto de Oliveira Magnago ${ }^{3}$
}

\begin{abstract}
Resumo: Os materiais utilizados para produzir o concreto são finitos na natureza. Pensando nisso, existem diversos estudos comprometidos a encontrar substitutos para os agregados, seja graúdo ou miúdo. Esses substitutos, podem ser resíduos naturais, tais como: fibras naturais ou casca de arroz e etc, ou resíduos industriais, como pneus ou embalagens PET. Nesse artigo, foi utilizado como substituto no agregado graúdo, a Placa de Circuito Impresso (PCl), em proporções de 10\%, 20\% e 30\%. As PCl's são encontradas nos Resíduos de Equipamentos Eletro Eletrônicos (REEE). Para a realização dos testes, foi feita a extração dos componentes e feito a moagem num moinho de facas, onde a PCl foi moída duas vezes. Após isso, foram feitos os moldes e realizados os ensaios de resistência à compressão e resistência à tração na flexão, para testar a viabilidade técnica. Atingiu-se a resistência de 25,67 MPa no ensaio de compressão para o concreto padrão e a resistência de 24,53 MPa na proporção de $10 \%$ para o ensaio de compressão. Para o ensaio de tração na flexão, a resistência atingida foi de 5,19 MPa para concreto padrão e de 3,81 MPa para a proporção de $30 \%$. Sendo assim, sua aplicação como concreto não estrutural é possível.

Palavras-chave: Reciclagem; concreto; PCl; agregados graúdo; REEE.
\end{abstract}

Abstract: The materials used to produce concrete are finite in nature. With this in mind, there are several studies committed to finding substitutes for households, whether large or small. These substitutes may be natural wastes such as: natural fibers or rice husk, among others, or industrial wastes such as tires or PET packaging. In this article, the Printed Circuit Board (PCI) was used as a substitute in the coarse aggregate, in proportions of $10 \%, 20 \%$ and $30 \%$. PCls are found in Waste Electronic Equipment (WEEE). To perform the tests, the components were extracted and milled in a knife mill, where the PCI was milled twice. After that, the molds were made and the compressive strength and flexural tensile strength tests were performed to test the technical feasibility. The resistance of 25.67 MPa was reached in the compression test for standard concrete and the resistance of $24.53 \mathrm{MPa}$ in the proportion of $10 \%$ for the compression test. For the flexural tensile test, the strength achieved was $5.19 \mathrm{MPa}$ for standard concrete and 3.81 MPa for the proportion of $30 \%$. Thus, its application as non-structural concrete is possible.

Keywords: Recycling; concrete; PCB; coarse aggregates; WEEE.

\footnotetext{
1 Mestrando em Mestrado Profissional em Materiais pela UniFOA Volta Redonda, RJ, BRASIL. E-mail: lacalves1@hotmail.com.

2 Doutor em Ciência dos Materiais, Professor Responsável Doutor do Centro Universitário Geraldo Di Biase (UGB). E-mail: ricfisic@gmail.com.

3 Doutor em Física, Coordenador do MeMat UniFOA Volta Redonda, RJ, BRASIL, E-mail: roberto.magnago@foa.org.br.
} 


\section{INTRODUÇÂO}

Atualmente, o concreto é o material mais utilizado na construção civil. No seu estado fresco, o concreto toma a forma do molde onde será aplicado. Suas principais propriedades são a trabalhabilidade e a homogeneidade, sendo muito fácil de fazer. $A$ mistura é a base de cimento portland, areia, brita e água. Porém, como a brita e areia estão se tornando produtos escassos nas grandes cidades e $40 \%$ dos recursos extraídos são para ser utilizados na construção civil, é necessário pesquisas para procura de novos agregados (MODRO et al., 2009). Diversas pesquisas estão sendo realizadas, visando diminuir esse consumo ao mesmo tempo em que se aproveitam outros materiais disponíveis, que seriam jogados em aterros e lixões de forma inadequada e levariam décadas para se decompor. Podem ser resíduos industrializados, por exemplo, os pneus e embalagem PET e resíduos naturais, tais como: casca de arroz, serragem, ou bagaço da cana.

Dentre tantos materiais pesquisados, ainda há o "lixo eletrônico", mais conhecido como Resíduo de Equipamento Eletro Eletrônico (REEE), que são as TVs, geladeiras, computadores entre outros. Dentro estes REEE, encontram-se as Placas de Circuito Impresso $(\mathrm{PCl})$, as responsáveis por controlar as funções dos equipamentos eletro eletrônicas (EEE). Quando descartados incorretamente em lixões ou aterros, podem contaminar o meio ambiente.

As $\mathrm{PCl}$ 's podem ser feitas de diversos materiais, os mais comuns são: fenolite e fibra de vidro/epóxi. Existem ainda as PCl's feitas de poliéster e poliimida. Sua utilização varia de acordo com a necessidade, dependendo do material a ser utilizado, apresenta baixo custo, boa resistência térmica ou mecânica. As PCl's são projetadas para ter baixa inflamabilidade, baixa absorção de água, boa estabilidade dimensional entre outros.

Ao fazer o reaproveitamento das $\mathrm{PCl}^{\prime}$, podem ser evitadas a exploração de recursos naturais virgens e não renováveis. Podem-se reaproveitar os metais nobres de alto valor na cadeia de produção e as partes não metálicas das PCl's, como substitutos da brita no concreto. A PCl é um material pouco explorado em termos de pesquisa no país, onde se aproveita um tipo de metal da sucata de $\mathrm{PCl}$ ou adicionar em pequenas proporções $\mathrm{PCl}$ na fabricação de blocos de alvenaria.

Nos países com hábito de reciclar o REEE, a reciclagem realiza-se da seguinte forma: desmontagem e separação dos componentes valiosos, que passa por um tratamento especial; processamento mecânico e/ou metalúrgico e purificação dos materiais por processos químicos (OLIVEIRA; BERNARDES; GERBASE, 2012).

O objetivo desse estudo foi apresentar outro material possível de se aplicar ao concreto, substituindo o agregado graúdo por $\mathrm{PCl}$, em proporções de $10 \%$, $20 \%$ e $30 \%$, fazendo a comparação com o concreto padrão e identificar a proporção que tenha o melhor desempenho de resistência mecânica. Além disso, ajudará a dar um destino adequado aos resíduos, diminuindo a extração de matéria prima e gerando redução de 
custos.

\section{MATERIAIS E METODOS}

\subsection{Materiais}

Os materiais usados para este artigo foram: o concreto, usando brita, areia, $\mathrm{PCl}$ e água. O traço usado para o concreto padrão foi 1:2:3, na ordem, 7 litros de cimento, 14 litros de areia e 21 litros de brita. O cimento Portland, CP-III 40 RS de $40 \mathrm{MPa}$, embalagem de $50 \mathrm{~kg}$ da marca CSN, fornecido pela UniFOA. Brita 1 (diâmetro de 4,8 $\mathrm{mm}$ a $12,5 \mathrm{~mm}$ ) e 2 (diâmetro de $12,5 \mathrm{~mm}$ a $25 \mathrm{~mm}$ ) que foi gentilmente fornecida pela UniFOA. Foi utilizada a areia de tamanho médio de $0,42 \mathrm{~mm}$ a $1,2 \mathrm{~mm}$ que foi gentilmente fornecida pela UniFOA. Foi usada água potável, fornecida pela rede de abastecimento do SAAE de Volta Redonda. As PCl's foram coletadas basicamente na escola ICT/Fasf e na Kadoshi Informática, localizadas em Volta Redonda. Em maior parte, formadas por placa-mãe de computador.

\subsection{Métodos}

Na primeira etapa, foi realizada a limpeza das PCl's manualmente, extraindo os componentes maiores, exemplo das entradas USB, baterias, memórias entre outros. Alguns plásticos, pontos de solda e metais, foram processados juntos, devido à dificuldade da retirada e para não gerar mais resíduos. Após isso, as placas foram moídas duas vezes em um moinho de facas, modelo Plastimax, modelo PM 200.

Os corpos de prova utilizados neste trabalho, baseados na norma NBR $5738 / 2003$, foram produzidos no Laboratório do UniFOA, com o traço 1:2:3, na ordem, cimento, areia, brita e a água foi sendo adicionada conforme a necessidade. Foram produzidos um total de $12 \mathrm{cps}$ para cada porcentagem, além do $\mathrm{cp}$ padrão, considerando as idades da amostra para o teste $(7,14,21$ e 28 dias). De posse dos materiais, a mistura do concreto foi feita na Betoneira, marca Menegotti, de 150 litros, modelo Premium. Na produção dos corpos de prova (cp) para compressão, começou pelo cp referência onde foram usados 7 litros de cimento, 14 litros de areia e 21 litros de Brita (1 e 2). Para as proporções de 10\%, 20\% e 30\%, a PCl substituiu a Brita, conforme Tabela 1. A água foi adicionada individualmente para cada proporção.

A produção dos corpos de prova de tração tem como diferenças, a quantidade de material utilizado, devido ao teste ser realizado apenas na idade de 28 dias, conforme Tabela 2 e a mistura foi feita manualmente.

Para o ensaio de compressão, as formas utilizadas para o molde dos corpos de prova foram de metal, lisas e revestidas com uma fina camada de óleo e com dispositivo de abertura para facilitar na hora de moldar, com dimensão de $10 \times 20 \mathrm{~cm}$. Os cp's foram preenchidos em duas etapas, entre elas, foi desferido 12 golpes com uma haste, deixando o concreto mais uniforme possível no molde e foi utilizado uma colher de pedreiro para o último acabamento, baseado na NBR 5738 (ASSOCIAÇÃO 
BRASILEIRA DE NORMAS TÉCNICAS, 2003).

Para o ensaio de tração, as formas utilizadas para o molde dos corpos de prova foram de madeira naval, fabricada no UniFOA, com dimensão de $35 \times 10 \times 10 \mathrm{~cm}$. Os cp's foram preenchidos em duas etapas, entre elas, foi desferido 12 golpes com uma haste, deixando o concreto mais uniforme possível no molde e foi utilizado uma colher de pedreiro para o último acabamento, baseado na NBR 5738 (ASSOCIAÇÃO BRASILEIRA DE NORMAS TÉCNICAS, 2003).

Tabela 1 - Proporção de material usado para cada porcentagem de CP para resistência à compressão.

\begin{tabular}{cccccc}
\hline \multirow{5}{*}{$\%$} & \multicolumn{5}{c}{ Material (litros) } \\
\cline { 2 - 6 } & Areia & Água & Brita & PCl & Cimento \\
\hline 0 & 14 & 4 & 21 & - & 7 \\
\hline 10 & 14 & 4 & 18,9 & 2,1 & 7 \\
\hline 20 & 14 & 3,9 & 16,8 & 4,2 & 7 \\
\hline 30 & 14 & 4,2 & 14,7 & 6,3 & 7 \\
\hline
\end{tabular}

Fonte: Os autores.

Tabela 2 - Proporção de material usado para cada porcentagem de CP para resistência à tração na flexão.

\begin{tabular}{cccccc}
\hline & \multicolumn{5}{c}{ Material (litros) } \\
\cline { 2 - 6 } & Areia & Água & Brita & PCl & Cimento \\
\hline 0 & 4 & 1 & 6 & - & 2 \\
\hline 10 & 4 & & 5,4 & 0,6 & 2 \\
\hline 20 & 4 & 1 & 4,8 & 1,2 & 2 \\
\hline 30 & 4 & 1 & 4,2 & 1,8 & 2 \\
\hline
\end{tabular}

Fonte: Os autores.

\subsubsection{Ensaio de resistência à compressão}

O Ensaio de resistência à compreensão foi realizado no Laboratório da UniFOA, com base na NBR 5739 (ASSOCIAÇÃO BRASILEIRA DE NORMAS TÉCNICAS, 2007), foi utilizada a prensa EMIC, modelo PC 150, célula de carga de 15.000 toneladas, com capacidade máxima de $100 \mathrm{MPa}$, com base de neoprene tanto em cima como embaixo do corpo de prova, de modo que se tenha melhor distribuição de carga no CP até se romper. Taxa de carregamento utilizada foi de $0,7 \mathrm{MPa} / \mathrm{min}$. 


\subsubsection{Ensaio de resistência à tração na flexão}

O Ensaio de Resistência à tração na flexão realizado no Laboratório da UniFOA, com base na NBR 12142 (ASSOCIAÇÃO BRASILEIRA DE NORMAS TÉCNICAS, 2010), foi utilizado a prensa EMIC, modelo PC 150, célula de carga de 15.000 toneladas, com capacidade máxima de $100 \mathrm{MPa}$, com base de neoprene tanto em cima como embaixo do corpo de prova, de modo que se tenha melhor distribuição de carga no CP até se romper. Taxa de carregamento utilizada foi de $0,9 \mathrm{MPa} / \mathrm{min}$.

\section{Resultado e Discussão}

Para o ensaio de resistência à compressão, os resultados apresentados nas Figuras $(1,2,3,4)$, foram separados de acordo com a idade do corpo de prova $(7,14$, 21 e 28 dias), tendo como parâmetro, os corpos de prova padrão. Para o ensaio de resistência à flexão, os resultados apresentados na Figura 6 , considera apenas a idade de 28 dias, tendo como parâmetro, os corpos de prova padrão.

\subsection{Ensaio de Resistência à Compressão}

\subsubsection{Resultados para sete dias}

Para o resultado de sete dias, observa-se que em relação ao corpo de prova padrão, a amostra de $20 \%$ foi a que obteve os melhores resultados. Pode ter acontecido de o material ao ser despejado na forma, não ter ficado homogêneo, podendo ter mais areia ou PCI, por exemplo, (PARAGUASSÚ, 2017). Pode ser o caso da amostra de $10 \%$. A Figura 1 ajuda a melhor visualização dos resultados. Resultados obtidos nesse estudo são parecidos com resultados obtidos de (NAGAJOTHI; KALA, 2015).

Figura 1 - Resultado do ensaio de compressão com sete dias.

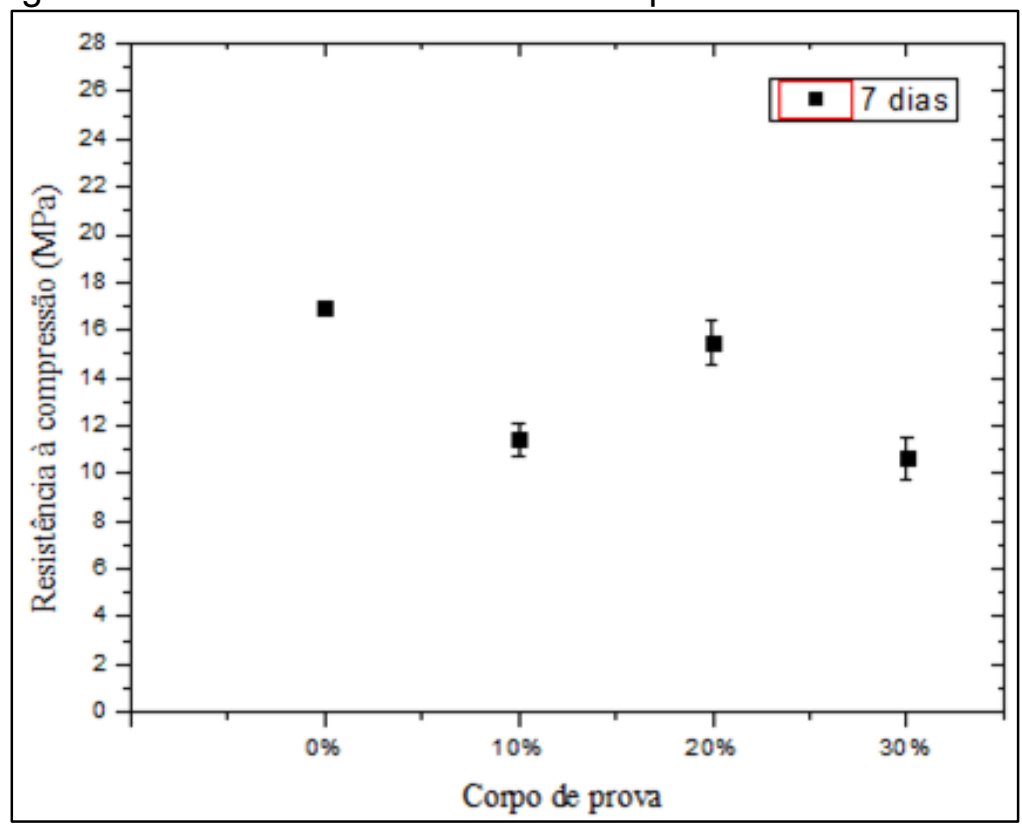

Fonte: Os autores. 


\subsubsection{Resultados para 14 dias}

Para o resultado de 14 dias, destaca-se que a amostra de $20 \%$ de $\mathrm{PCl}$ teve uma queda na resistência em relação ao resultado de sete dias. (FERRARI et al., 2018) diz que o formato e tamanho da $\mathrm{PCI}$ pode ter influência no resultado. Essa queda pode ser atribuída também à natureza angular da $\mathrm{PCI}$, menor que do agregado graúdo, fazendo assim a resistência cair (WANG; ADAWAY, 2015). Em outra hipótese, o material ao ser despejado na forma, não ter ficado homogêneo, podendo ter mais areia ou $\mathrm{PCl}$, por exemplo, (PARAGUASSÚ, 2017). Os resultados são apresentados Figura 2.

Figura 2 - Resultados do ensaio de compressão para 14 dias.

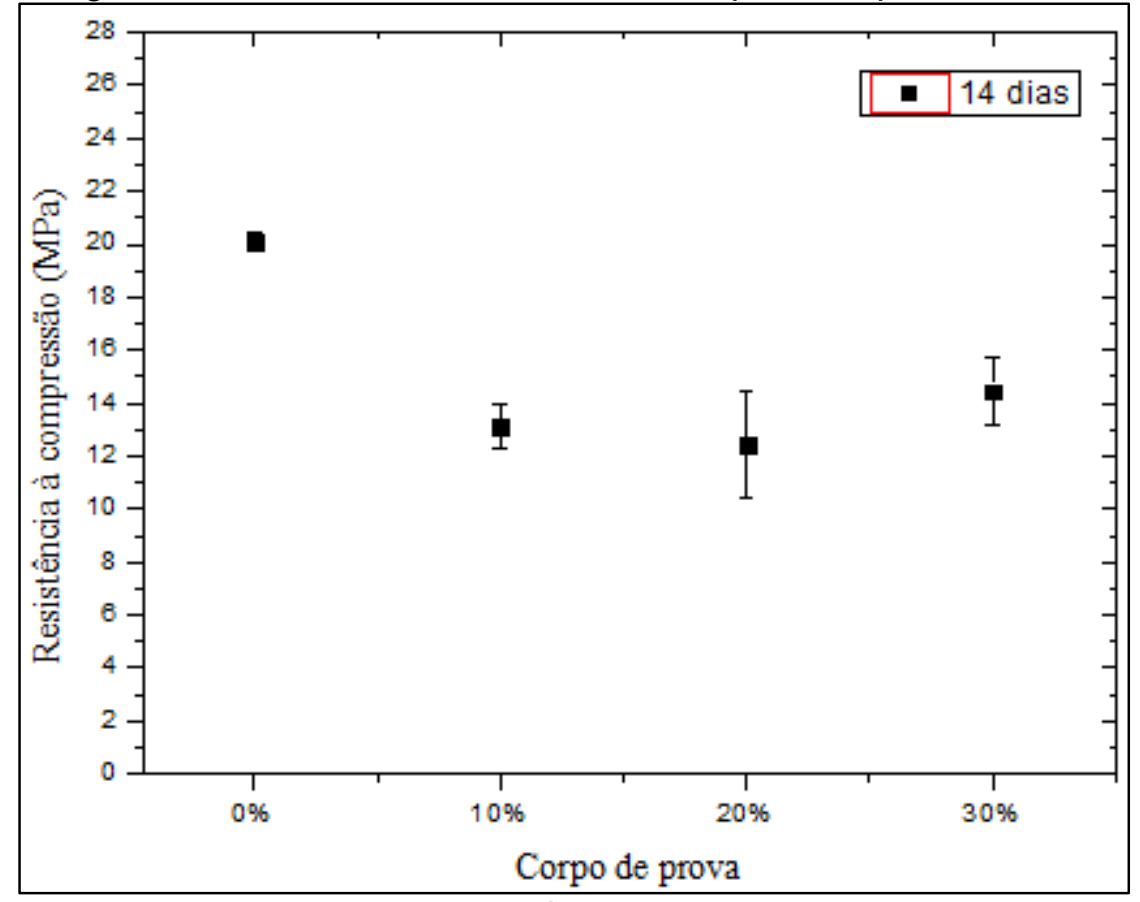

Fonte: Os autores.

\subsubsection{Resultados para 21 dias}

Os resultados de 21 dias são apresentados na Figura 3. Na cura dos corpos de prova na idade de 21 dias, em média, o ganho de resistência foi de $30 \%$ para as proporções com $10 \%$ e $20 \%$ com PCl. Para a proporção de $30 \%$ de $\mathrm{PCl}$, o ganho foi de aproximadamente $20 \%$ de resistência. Resultados obtidos nesse estudo são parecidos com resultados obtidos de (NAGAJOTHI; KALA, 2015). 
Figura 3 - Resultados do ensaio de compressão para 21 dias.

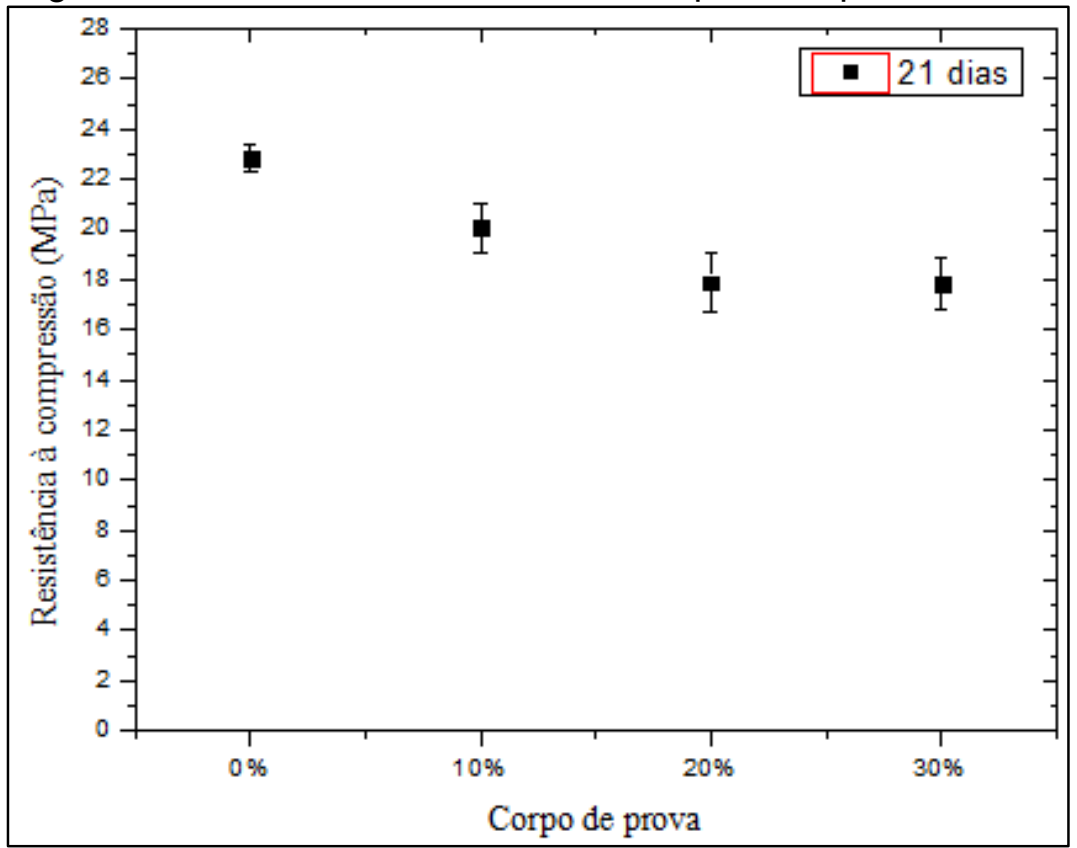

Fonte: Os autores.

\subsubsection{Resultados para 28 dias}

É nesta idade de cura em que se considera os valores para realizar projetos. Considerando que não foi usado nenhum aditivo para auxiliar a secagem ou obter ganho de resistência, as amostras com $10 \%$ e $20 \%$ de $\mathrm{PCl}$ atingiram valores próximos a amostra padrão, conforme apresentado na Figura 4. Estas amostras podem ter ficado mais homogêneas (PARAGUASSÚ, 2017). Resultados obtidos nesse estudo são parecidos com resultados obtidos de (NAGAJOTHI; KALA, 2015).

Figura 4 - Resultados do ensaio de compressão para 28 dias.

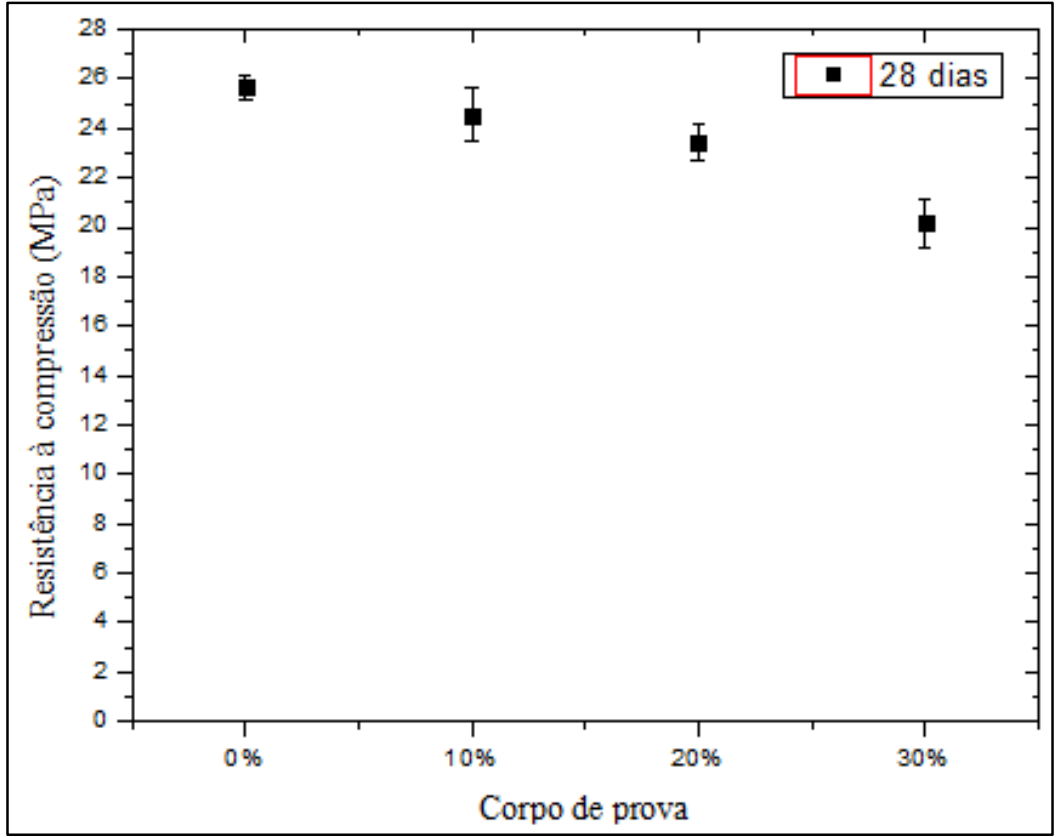

Fonte: Os autores. 


\subsubsection{Tensão (MPa) x Idade dos corpos de prova}

A Figura 5 mostra a evolução das amostras ao longo dos 28 dias de cura. Podese destacar a composição de $10 \%$ de $\mathrm{PCl}$, que aos 28 dias atingiu o equivalente a $95 \%$ da tensão total da amostra padrão e a composição de $20 \%$ que atingiu $91,3 \%$ da tensão total. (OLOFINNADE; EDE; NDAMBUKI, 2017; THORNEYCROFT et al., 2017), dizem que, tanto a forma e tamanho das partículas do $\mathrm{PCl}$, assim como, a superfície mais lisa do PCl podem ser a explicação para a perda de resistência. (THORNEYCROFT et al., 2017), complementa afirmando que as PCl's podem agir como defeito na estrutura interna do concreto. (WANG; ADAWAY, 2015), diz que, quanto menor o tamanho das partículas melhor seria a interação entre pasta e da $\mathrm{PCl}$.

Figura 5 - Evolução da Tensão (MPa) x Dias.

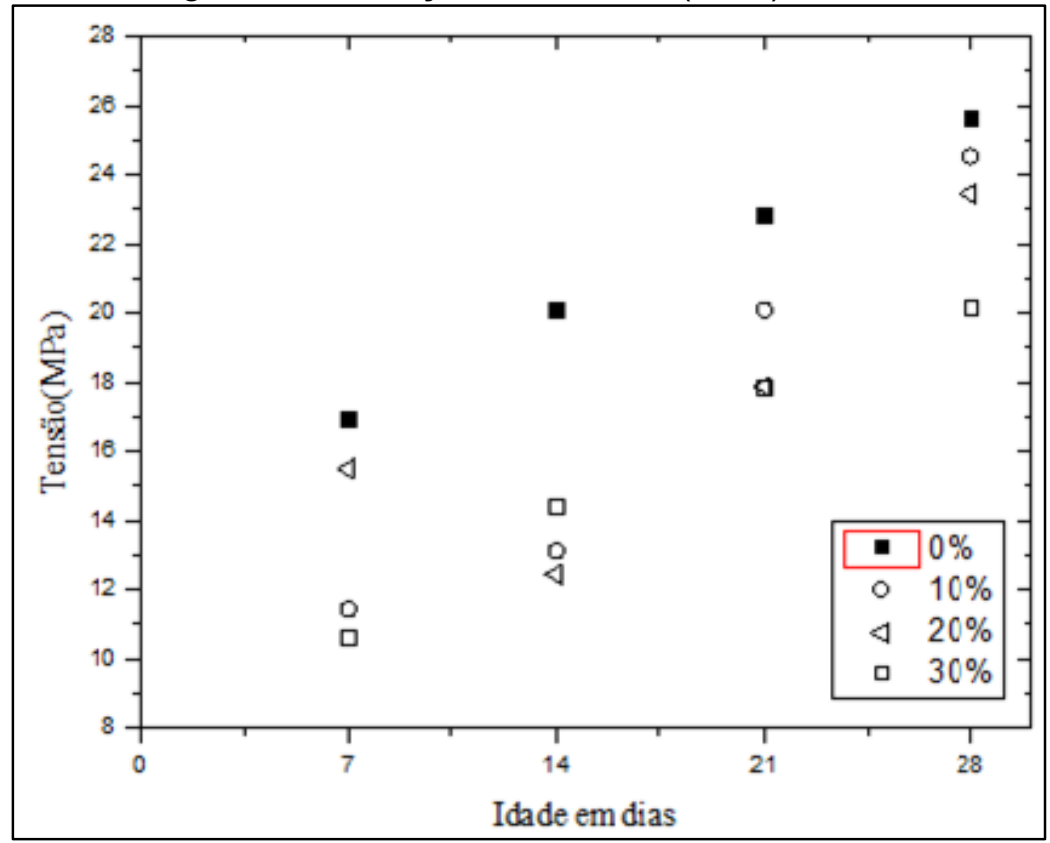

Fonte: Os autores.

\subsection{Ensaio de Resistência à Tração na Flexão}

Para o ensaio de resistência à tração na flexão, o resultado foi apresentado na Figura 6, tendo como parâmetro, os corpos de prova padrão.

Ensaio muito utilizado para verificar, por exemplo, os efeitos que o concreto sofrerá ao ser usado como piso ou viga. Pela literatura, esse ensaio resiste em média até $10 \%$ do valor da resistência a compressão. Na Figura 6, foi possível observar que, para o cimento com $30 \%$ de $\mathrm{PCl}$ ocorreu um aumento de resistência à tração na flexão, ficando fora da faixa esperada para este tipo de ensaio. Após pesquisas na literatura, foi levantada a hipótese para essa inesperada melhora, o fator água/cimento e uma mistura mais homogênea dos materiais (ANNA, 2013). Em outra hipótese, o que pode ter acontecido, foi que o concreto absorveu a propriedades/caracteristica da $\mathrm{PCl}$, que tem boa resistência a flexão na tração (MAGNAGO, 2014; ANNA, 2013). Outra hipótese levantada na literatura por (OLOFINNADE; EDE; NDAMBUKI, 2017), diz que a força de 
ligação entre cimento e $\mathrm{PCl}$ são fracas, o que provoca a perda de resistência. Os valores ficaram próximos aos atingido por Alagusankareswari, 2016 (ALAGUSANKARESWARI et al., 2016).

Figura 6 - Resultado do ensaio de tração na flexão com 28 dias.

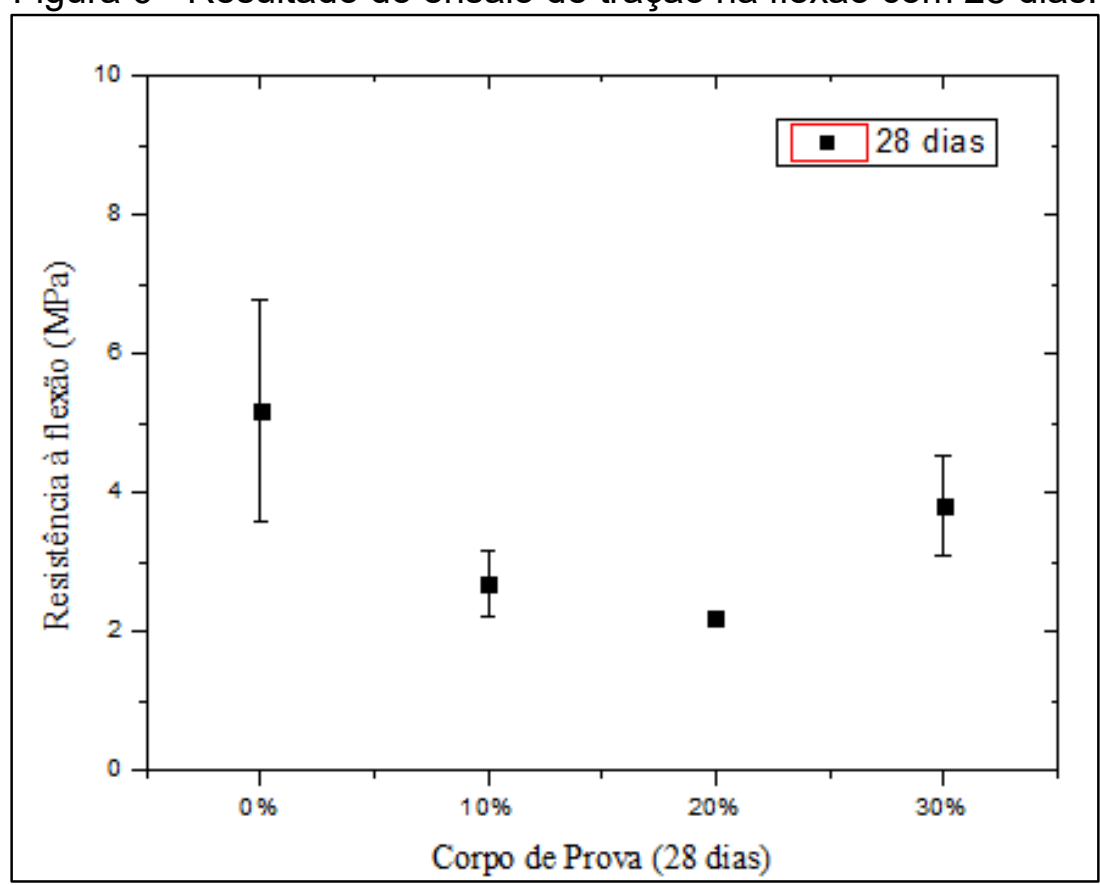

Fonte: Os autores.

\section{CONCLUSÃO}

Baseado nas normas NBR 6118/2014 e NBR 12655/2006, para o concreto ser considerado estrutural, deve apresentar valores entre $20 \mathrm{MPa}$ a $90 \mathrm{MPa}$. Os valores das amostras produzidas neste trabalho apresentam valores $25,67 \mathrm{MPa}$ de resistência à compressão para amostra padrão e $24,53 \mathrm{MPa}$ de resistência à compressão para amostra de $10 \%$ com PCl. Para o ensaio da resistência à tração na flexão, a amostra com $30 \%$ de $\mathrm{PCl}$ obteve o melhor desempenho entre as amostras com $\mathrm{PCl}$. Pelas normas, é necessário aplicar um fator de segurança e aplicando o maior índice, o concreto cai para abaixo de $20 \mathrm{MPa}$, não sendo possível a utilização como concreto estrutural, mas está apto a ser utilizado como concreto não estrutural, podendo ser aplicado em calçadas ou pavimentos (ASSOCIAÇÃO BRASILEIRA DE NORMAS TÉCNICAS, 2014; 2006).

\section{AGRADECIMENTOS}

Agradeço ao Prof. Dr. Roberto de Oliveira Magnago, a UniFOA, que cedeu os materiais para produção do concreto, à escola ICT/Fasp, localizada na cidade de Volta Redonda - RJ e Loja de informática Kadoshi, localizada na cidade de Volta Redonda $\mathrm{RJ}$, por ceder as PCl's e aos técnicos de laboratório Arthur Almeida Bitencourt e Dirceu Hartung de Camargo, pela ajuda durante os ensaios. 


\section{REFERÊNCIAS}

ALAGUSANKARESWARI, K.; SANDEEP, K. S.; VIGNESH, K. B.; NIYAS, K. A. H. Na Experimental Study on E Wast Concrete. Indian Journal of Science and Technology, v. 9, n. 2, 2016.

ANNA, A. S. Characteristics of concrete building units containing crushed waste glass. 201386 f. Dissertação (Mestrado em Master os Science) North Dakota State University of Agriculture and Applied Science, 2013.

ASSOCIAÇÃO BRASILEIRA DE NORMAS TÉCNICAS. NBR 5738: Concreto Procedimento para moldagem e cura de corpos-de-prova. Rio de Janeiro: ABNT, 2003.

ASSOCIAÇÃO BRASILEIRA DE NORMAS TÉCNICAS. NBR 12655: Concreto de cimento Portland - Preparo, controle e recebimento - Procedimento. Rio de Janeiro: ABNT, 2006.

ASSOCIAÇÃO BRASILEIRA DE NORMAS TÉCNICAS. NBR 5739: Concreto - Ensaio de compressão de corpos-de-prova cilíndricos - Método de ensaio. Rio de Janeiro: ABNT, 2007.

ASSOCIAÇÃO BRASILEIRA DE NORMAS TÉCNICAS. NBR 12142: Concreto Determinação da resistência à tração na flexão de corpos de prova prismáticos. Rio de Janeiro: ABNT, 2010.

ASSOCIAÇÃO BRASILEIRA DE NORMAS TÉCNICAS. NBR 6118: Projeto de estruturas de concreto - Procedimento. Rio de Janeiro: ABNT, 2014.

FERRARI, J. R. et al. Reaproveitamento de placas de circuito impresso na produção de argamassas. In: CBECiMat - CONGRESSO BRASILEIRO DE ENGENHARIA E CIÊNCIA DOS MATERIAIS, 23., 2018. Anais... Foz do Iguaçu, 2018. 12 p.

MAGNAGO, R. O.; AMARAL, M. P.; MULINARI, D. R.; SANTOS, C. Preparação e caracterização de compósitos obtidos a partir de rejeitos poliméricos oriundos de placas de equipamentos eletrônicos. In: CBECIMAT - CONGRESSO BRASILEIRO DE ENGENHARIA E CIÊNCIA DOS MATERIAIS, 21., 2014. Anais... Cuiabá, MT Brasil, 2014.

MODRO, N. L. R. et al. Avaliação de concreto de cimento Portland contendo resíduos de PET. Revista Matéria, v. 14, n. 1, p. 725-736, 2009.

NAGAJOTHI, P. G.; KALA, F. A Study on reusing waste printed circuit board powders and chips in cement mixes. International Journal of Earth Sciences and Engineering, v. 8, n. 2, p. 460-464, abril, 2015.

OLIVEIRA, C. R., BERNARDES, A. M.; GERBASE, A. E. Collection and recycling of eletronic scrap: A worldwide overview and comparison with the Brazilian situation. Waste Management, v. 32, n. 8, p. 1592-1610, 2012.

OLOFINNADE, O.M.; EDE, A.N.; NDAMBUKI, J.M. Sustainable greem environment through utilization of waste soda-lime glass for production of concrete. JMES, v. 8, n. 4, p. 1139-1152, 2017.

PARAGUASSÚ, I. M. Elaboração de endurecedor químico de superfície à base de silicato de sódio e silicado de lítio para aplicação em pavimentos de concreto. 
201789 f. Dissertação (Mestrado Profissional em Materiais) - Centro Universitário de Volta Redonda - UniFOA, Volta Redonda, 2017.

THORNEYCROFT, J. et al. Performance of structural conccrete with recycled plastic waste as a partial replacement for sand. Construction and Building Materials, v. 161, p. 63-69, 2017.

WANG, Y.; ADAWAY, M. Recycled glass as a partial replacement for fine aggregate in sctructural concrete - Effects on compressive strength. Special Issue: Eletronic Journal of Structural Engineering, v. 14, n. 1, p. 116-122, 2015. 